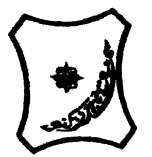

Bayero Journal of Pure and Applied Sciences: 10(1): 304 - 310

ISSN 2006 - 6996

\title{
FIXED-BED COLUMN ADSORPTION OF METHYL BLUE USING CARBON DERIVED FROM AXLE-WOOD (Anogeissus leiocarpus) STEM AS ADSORSENT
}

\author{
Yahuza K. M ${ }^{1} .{ }^{*}$, Ibrahim M. B ${ }^{2}$., Ayuba A. M․ , Hamza R. S $^{1}$. \\ ${ }^{* 1}$ Department of Chemistry, Faculty of Science, Abubakar Tafawa Balewa University Bauchi, Nigeria \\ ${ }^{2}$ Department of Pure and Industrial Chemistry, Faculty of Science, Bayero University Kano, Nigeria \\ - Corresponding Author:yahuzakhuzaifa@gmail.com; mbibrahim.chm@buk.edu.ng
}

\begin{abstract}
Axle Wood Carbon (AWC) was used to study the removal of Methyl Blue (MB) from its aqueous solution in a fixed-bed column adsorption system. The adsorbent (AWC) was characterized using SEM and $\mathrm{pH}_{P Z C}$. SEM revealed the surface morphology and from the $\mathrm{pH}_{P Z C}$ determination, it was found that at $\mathrm{pH}$ of 8.21 the adsorbent has a net surface charge of zero. The column adsorption parameters were optimized and the maximum percentage removal was achieved by setting the level of process variables at $100 \mathrm{mg} / \mathrm{L}$ initial $\mathrm{MB}$ dye concentration, $28 \mathrm{~cm}$ bed height, and $3 \mathrm{~mL} / \mathrm{min}$ flow rate. The fixed-bed adsorption system was found to perform well with lower initial dye concentration, higher adsorbent bed height, and lower feed flow rate. The breakthrough curve obtained from the adsorption process was fitted into Adams-Bohart and Yoon-Nelson models. Yoon-Nelson model showed the time required to achieve $50 \%$ adsorbate breakthrough, $(\tau)$ agreed closely with the experimental data ( $\tau 50 \%$ exp.) whose value is 298. While Adams-Borhat model, gave 35.7885 as the volumetric sorption capacity of the bed $\left(\mathrm{N}_{0}\right)$. This implies that the column has reached first saturation level. As such AWC is effective for the removal of $M B$ and the selected kinetic models can be used to explain the column behaviours for the removal of $M B$ and also to predict the large scale industrial application of the process.

Key words: Axle wood Carbon, Breakthrough Curve, Column adsorption, Kinetic Model, Methyl Blue.
\end{abstract}

\section{INTRODUCTION}

Notwithstanding the most recent challenge militating against water pollution is the discharge of effluent from many industries to the water bodies which in turn affect not only aquatic life but resulting competition in consumption of pure water (Ayyappan et al., 2005). A significant amount of dye effluent in the water is noticeable and undesirable; and too much of it may lead to environmental degradation (Yu et al., 2009; Meena et al., 2005). Numerous research groups carried out laboratory based experiment in order to come up with a suitable method to mitigate or remove dyes from industrial effluent before discharge (Gupta et al., 2004). Fixed bed column adsorption which is one of the key, foremost and cost effective physical method in removing dyes from aqueous solution, was chosen in this study (Dawood and Sen, 2012; Mohammod et al., 2011). But, the method can only be effective if and only if good adsorbent was used. Recently agricultural by-products or waste materials were used as adsorbent by many research groups (Cui et al., 2008; Dawood and Sen, 2012) and it was found that they are good and inexpensive adsorbents, renewable and abundantly available (Vasques et al., 2009). Despite these adsorbents are good for adsorption process, they tend to be poor for continuous adsorption process through the column due to their surface area. Activated carbon derived from woods has potential of removing dyes completely from their aqueous solutions. There are quite a number of reported articles on adsorption study for the removal of dyes. Most of these articles were restricted to batch equilibrium studies. However, the data may not be applicable to most of the treatment systems such as column operations; where contact time is not sufficient for the attainment of equilibrium (Yagub et al., 2014; Sadaf and Bhatti, 2014; Agrawal and Bajpai, 2011). Furthermore, batch experimental data are often not easy to apply directly to fixed-bed column performance because isotherms are unable to give accurate data for scale up since a flow column is not at equilibrium. Hence, there is a need to perform adsorption study using fixed-bed columns. This fixed-bed column with adsorbents offers easy, continuous operation and scale up which is an important aspect of adsorption process. 
In addition, there are lesser number of adsorption results on column study compared to vast batch adsorption study, on inorganic/organic removal by various adsorbents, were reported which is also mentioned in recent review article by Yagub et al. (2013). Furthermore, there is paucity of research reported about methyl blue adsorption to activated carbon derive from Axle wood in column mode.

The aim of this current study was to invoke the optimization of process parameter such as bed height, initial methyl blue (MB) concentration, flow rate on percentage adsorption removal using activated carbon derive from Axle wood. This paper also provides detail information on column performance thereby testing YoonNelson and Adams Bohart kinetic models for column adsorption of $\mathrm{MB}$ from it aqueous solution. The result obtained from these models will help in developing a large scale model for continuous process.

\section{MATERIALS AND METHODS \\ Adsorbent Preparation}

Axle-wood stem Anogeissus leiocarpus called "Marke" in Hausa was collected locally from the bush near Langwami Village in Takai Local Government area of Kano State, Nigeria. The adsorbent was prepared in the same manner as described by Ajaero et al. (2010).

Adsorbent characterization

Scanning electron microscope (SEM, Leica Stereoscan-440) and Fourier transform infrared spectroscopy (Cary630) Agilent Technologies in a range of $4000-400 \mathrm{~cm}^{-1}, \mathrm{pH}_{\mathrm{pzc}}(\mathrm{pH}$ at point of zero charge) were used to investigate the physicochemical properties of the prepared adsorbent.

\section{Column Experiment}

A sintered column of $1 \times 50 \times 0.1 \mathrm{~cm}$ dimension was used to pack the adsorbents as slurry. Cotton wool was spread on top of the adsorbent to prevent its spillage on elution (Vasques et al., 2009). This involves mixing the adsorbent with sufficient amount of deionized water in a beaker and then poured into the

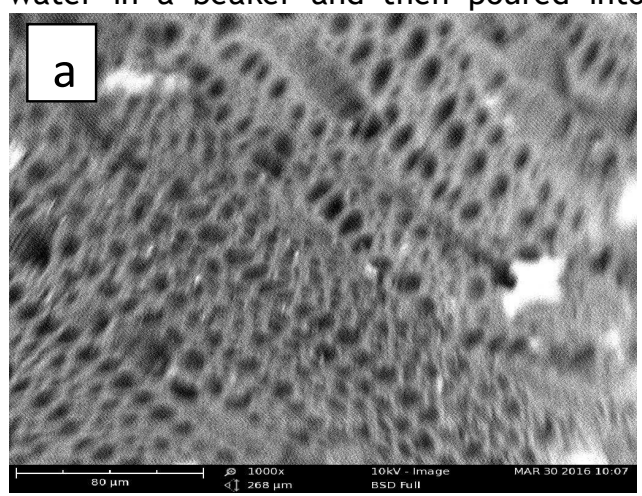

Fig 1: SEM images (a) before adsorption of $M B(b)$ after adsorption of the $M B$ column carefully. The stopcock was opened to allow the adsorbent to settle on gravitation and the lower meniscus of the water was kept just above the cotton wool to avoid letting the column to "run dry" (Sen et al., 2002). The reservoir of the dye solution $(250 \mathrm{ml}$ per run) was then opened to introduce it into the column in a down flow mode at an optimum flow rate of $3 \mathrm{ml} / \mathrm{min}$. The eluent fractions were collected after every 4 minutes and analyzed instantly for residual dye concentration using UV-spectrophotometer (Spectrum lab 23A Spectrophotometer No. 23A07107, Lemfield Medical England. Frequency $50 \mathrm{~Hz}$ ). The column was operated at room temperature throughout the experimentation. The percentage dye removal was calculated using equation (1):

\%Removal $=\left(\frac{C_{o}-C_{f}}{C_{0}}\right) \times 100$

Where $C_{f}$ is the concentration of adsorbate after adsorption and $C_{o}$ is the concentration of the adsorbate before adsorption.

$\mathrm{pH}$ at point of zero charge

The method of Tajana and Nikola (2006) was adopted in the determination of $\mathrm{pH}$ at point of zero charge $\left(\mathrm{pH}_{\mathrm{pzc}}\right)$ with little modification.

\section{RESULTS AND DISCUSSION}

Characterization of Adsorbent

Surface morphology of the adsorbent before and after adsorption process was determined by Scanning Electron Microscopy (SEM) as depicted in figure 1 below. From the figure, numerous cavities are clearly visible in the SEM micrograph of the adsorbent before adsorption, which appeared to have been covered or filled up by the adsorbate (methyl blue) after adsorption, signifying that the mass transfer zone due to layers of adsorbed molecules of dye has filled up the pores, the bulk of the adsorbent and even the surface of the substrate. The results of SEM found in this study are in good agreement with the finding of Nethaji et al. (2013).

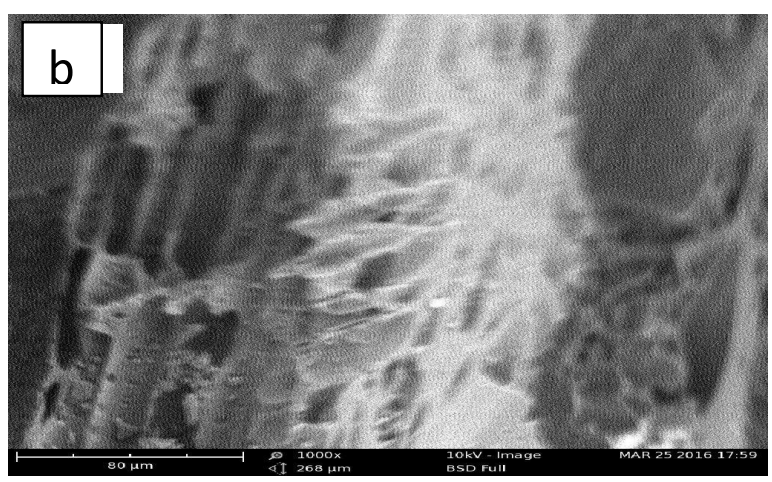


Fourier transform infrared spectroscopy (FTIR) was carried out on the fresh adsorbent as well as the used adsorbent obtained after adsorption of $M B$ to investigate the presence of functional groups and possible interaction between the dye molecules and the adsorbent. The spectra as shown in Fig 2 below, numerous peaks were observed from all FT-IR spectra in this work and they fall within the functional group regions of the spectrum. Therefore, they represent functional groups which are responsible for binding dye molecules to the surface of adsorbent and its bulk. Both spectra look very similar, with some noticeable variations. The major difference between the peaks in raw adsorbent spectrum and that of

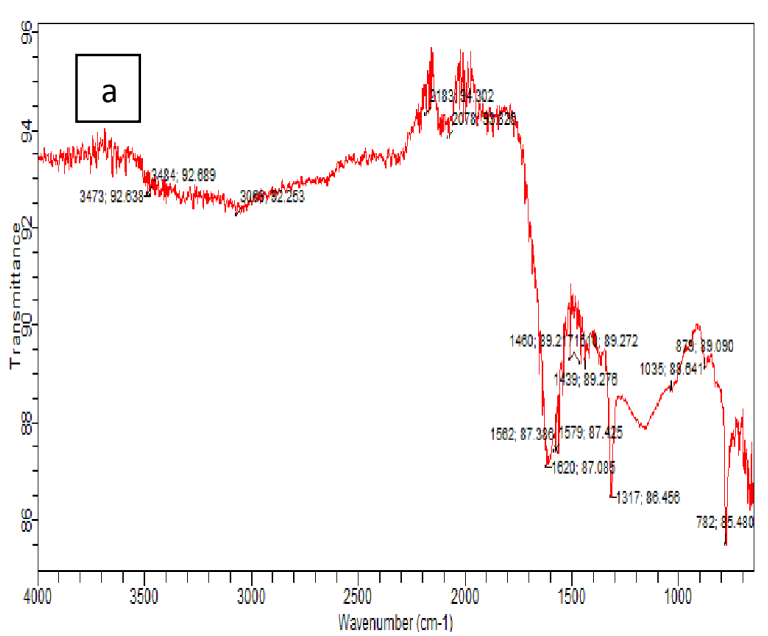

Fig 2 FT-IR spectra (a) raw adsorbent (b) adsorbent after adsorption of MB dye

$\mathrm{pH}_{\mathrm{PZC}}$ is a powerful technique in evaluating adsorption process. It provides information on the $\mathrm{pH}$ value at which the surface of a given adsorbent will have a net electrical charge density of zero (Tajana and Nikola, 2006). The graphical representation of the result is shown in Figure 3. The $\mathrm{pH}_{\mathrm{PzC}}$ of the adsorbent was found to be 8.21 in the basic region as, this

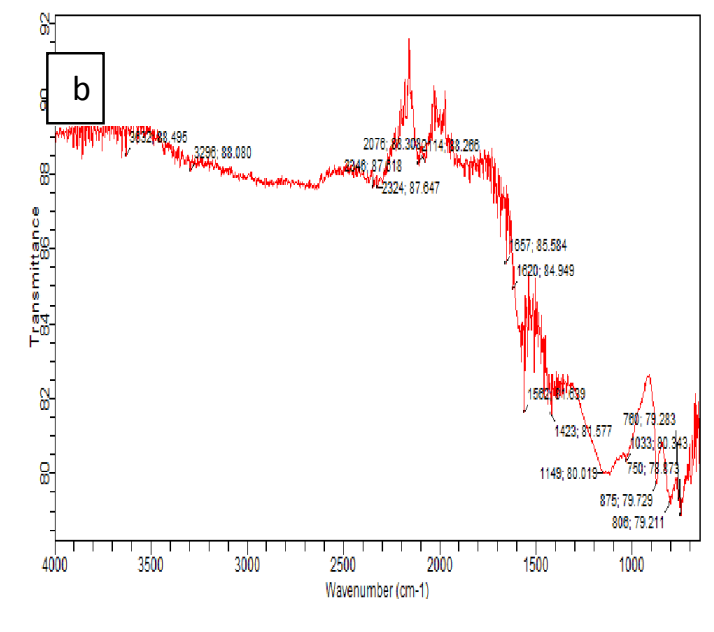

the adsorbent spectra after adsorption is the shifting of bands at $1317.86 \mathrm{~cm}^{-1}$ mainly associated to $\mathrm{C}-\mathrm{C}$ single bond and at $1620 \mathrm{~cm}^{-}$ ${ }^{1}$ attributed to $\mathrm{N}-\mathrm{H}$ stretching vibrations. Spectral band observed at the range of 2340$1680 \mathrm{~cm}^{-1}$ in almost all the figures indicate the presence of $\mathrm{C}=\mathrm{C}$ double bond, while peaks at the range of $1657-1423 \mathrm{~cm}^{-1}$ indicate the presence of $\mathrm{C}-\mathrm{N}$ and also confirms the presence of un-saturation in the spectra involving either raw dyes or after adsorption of the dyes. The peak at $1,263.48 \mathrm{~cm}^{-1}$ corresponds to $\mathrm{C}-\mathrm{N}$ stretching with amine or $\mathrm{C}-\mathrm{O}$ vibration. The peaks at $1,027.32 \mathrm{~cm}-1$ are possibly assigned to the $-\mathrm{C}-\mathrm{C}$ - stretching.

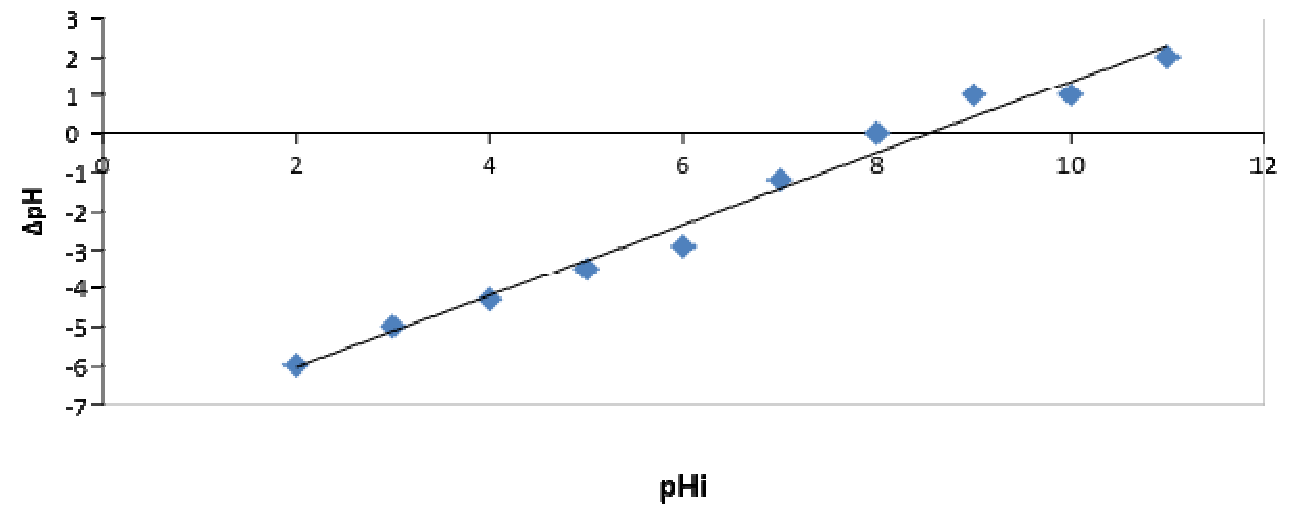

Fig: 3. Graph of $\mathrm{pH}_{\mathrm{PZC}}$ for the Adsorbent 
Optimization of Operational Parameter Influence of flow rate (contact time) on the adsorption process

The effect of flow rate on the adsorption of the $M B$ using carbon derived from Axle wood was investigated by varying the flow rate $(3,4,5$, and $6 \mathrm{ml} / \mathrm{min}$ ) while keeping other parameters fixed and the results obtained are presented in Figure 4. It was observed that the higher the flow rate, the higher the velocity of adsorption zone through the column and the lesser the contact time between the adsorbate and the substrate making it hard for the dye molecules to penetrate and diffuse deeply into the cavities of adsorbent. This results in decreased adsorption capacity and dye percentage removal. Reverse of this happened at lower flow rate as it gives room for longer contact time. $3 \mathrm{ml} / \mathrm{min}$ was adapted as the optimum flow rate throughout the experimentation having shown highest percentage removal at longest flow time as shown in Figure 4.

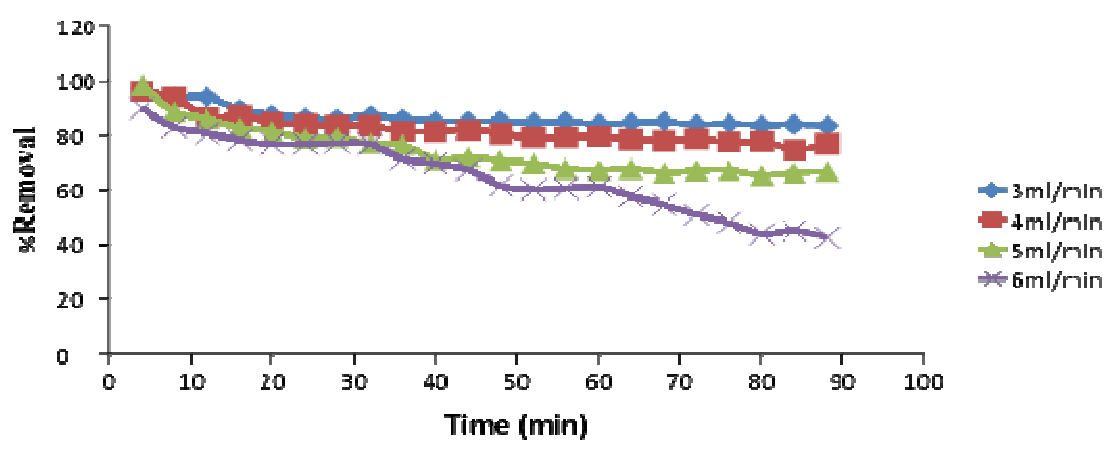

Figure 4: Influence of initial flow rate on percentage removal at constant initial dye concentration of $30 \mathrm{ppm}$, bed height of $28 \mathrm{~cm}$ and initial $\mathrm{pH}$ of the dye solution.

Influence of dye concentration on the adsorption process

The influence of initial dye concentration was studied and optimized by varying the influent dye concentration $(30,50,70$, and $100 \mathrm{ppm})$ at constant flow rate of $3 \mathrm{ml} / \mathrm{min}, 10 \mathrm{~g}$ adsorbent and ordinary $\mathrm{pH}$ of the solution. The effect was

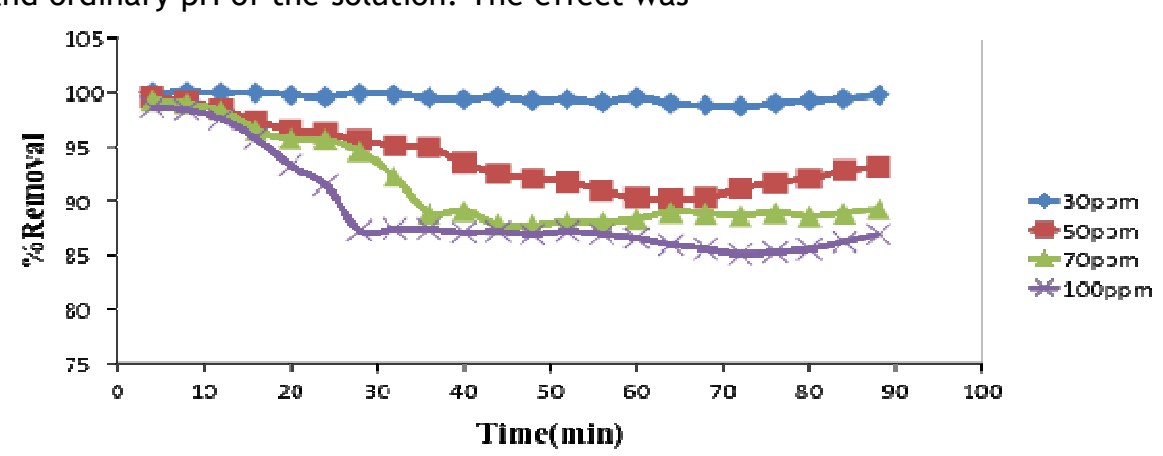

Figure 5: Influence of initial dye concentration on percentage removal at constant bed height 28 $\mathrm{cm}$, flow rate of $3 \mathrm{ml} / \mathrm{min}$ and initial $\mathrm{pH}$ of the dye solution

Influence of bed height (adsorbent dosage) on the adsorption process

Fig: 6 shows the curve obtained for MB dye adsorption on the adsorbent by packing different column bed heights of $6,9.5,15,22$ and $28 \mathrm{~cm}(2,4,6,8$ and $10 \mathrm{~g})$, at a fixed flow rate of $3 \mathrm{~mL} / \mathrm{min}$ and inlet dye concentrations of $30 \mathrm{mg} / \mathrm{L}$. The percentage removal per unit time as well as the treated volume increased expressed by plotting percentage removal against flow time for each concentration, as shown in figure $5.30 \mathrm{ppm}$ was the optimum concentration because it showed better removal at longer flow time with more treated volume. 


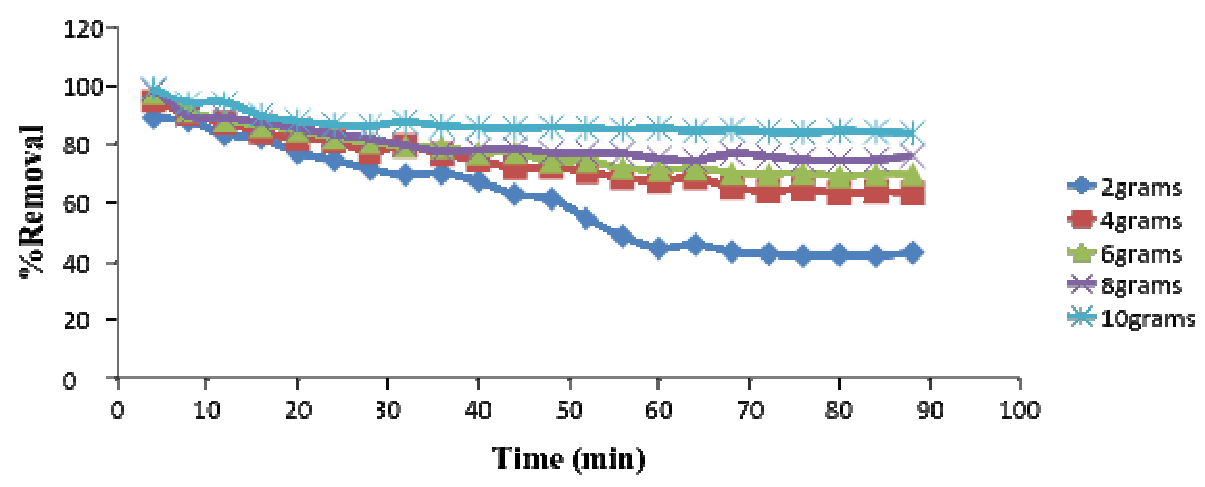

Figure 6: Influence of bed-height on percentage removal at constant flow rate of $3 \mathrm{ml} / \mathrm{min}$, initial dye concentration of $30 \mathrm{ppm}$ and $\mathrm{pH}$ of the dye

Influence of solution $\mathrm{pH}$ on the adsorption process

In this study, the $\mathrm{pH}$ of $\mathrm{MB}$ was adjusted using $0.1 \mathrm{M} \mathrm{HCl}$ (Sigma Aldrich, 98\%) and $\mathrm{NaOH}$ (Sigma Aldrich, 98\%) solutions across the $\mathrm{pH}$ scale as shown in Fig 7. MB decolorized rapidly at $\mathrm{pH} 8$ - minutes even before the adsorption process, but became more deeply coloured as it got more acidic at $\mathrm{pH} 2-4$ despite the fact that $\mathrm{MB}$ is acid dye, it gave negative percentage removal at $\mathrm{pH} 4-2$ due to the sharp change in colour from blue to dark purple-

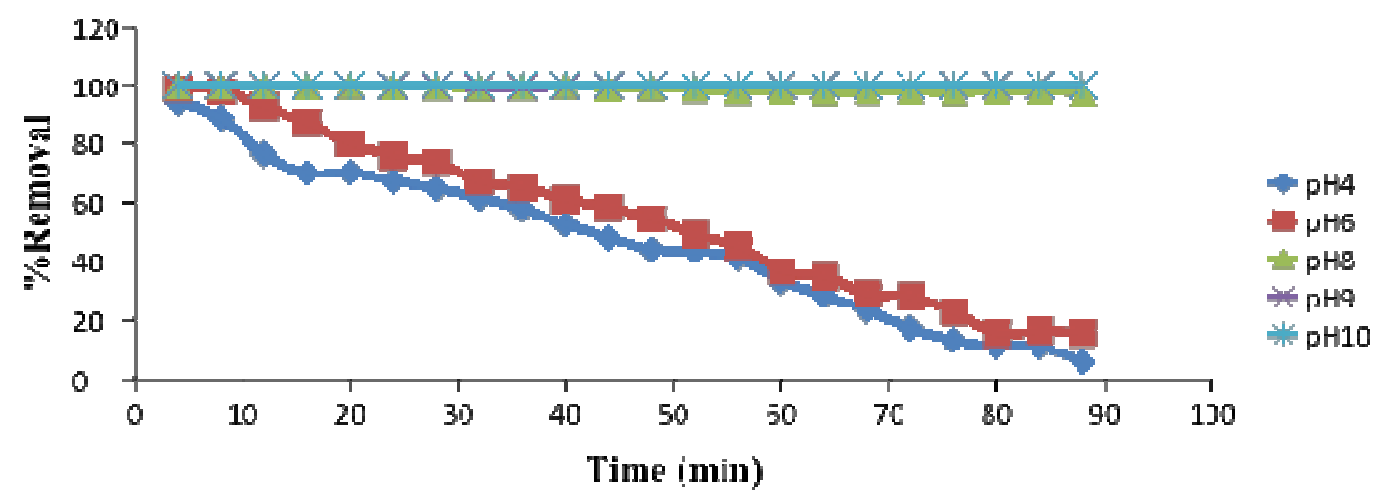

11 when it became colourless after some blue which has higher absorbance than the initial dye solution at the working wavelength.

Figure 7: Optimization of Solution $\mathrm{pH}$ for BM

\section{Analysis of column data}

The packed bed column was analyzed through the concept of the breakthrough curve. The breakthrough for the $M B$ dye used in this experiment at constant flow rate of $3 \mathrm{ml} / \mathrm{min}$ and 28 bed heights ( $10 \mathrm{~g}$ adsorbent) is shown in

Fig 8 . The breakthrough point is the center or

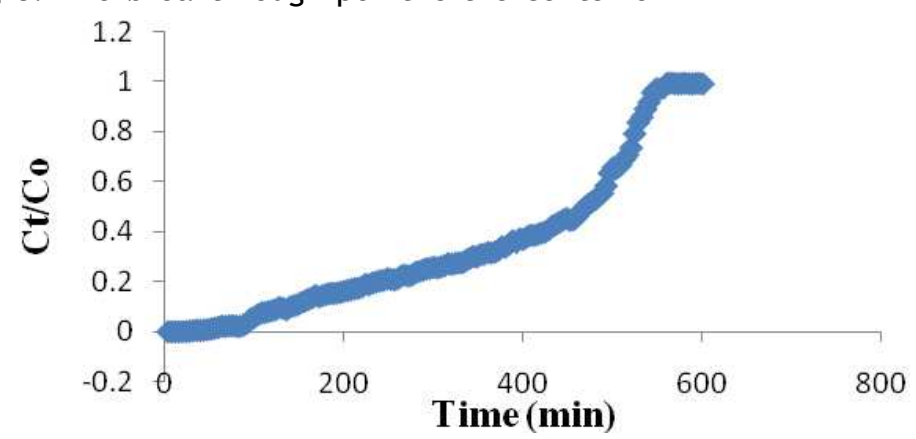

middle of the curve. That is around $340 \mathrm{~min}$ and normalized concentration of 0.6 . The total effluent volume $\left(V_{\text {eff }}\right)$ was $1.536 \mathrm{~L}$ before getting saturated and corresponding amount adsorbed $\mathrm{q}_{\mathrm{e}}(\mathrm{mg} / \mathrm{g})$ at breakthrough point of $5.406 \mathrm{mg} / \mathrm{g}$ was obtained in this study. 
Figure 8: Break-Through Curve For BM Dye Modeling of Column Data

Two mathematical models, Adams-Bohart model (Bohart and Adams, 1920) and YoonNelson model (Yoon and Nelson, 1984) were used in modelling of the data obtained from the present study. The linear form of the equations are (2) and (3) respectively;

$$
\begin{aligned}
& \text { Adam } \\
& \ln \left(\frac{\mathrm{C}_{\mathrm{t}}}{\mathrm{C}_{\mathrm{o}}}\right)=\mathbf{k}_{\mathrm{AB}} \mathrm{C}_{\mathrm{o}} \mathrm{t}-\mathbf{k}_{\mathrm{AB}} \mathrm{N}_{\mathrm{o}}\left(\frac{Z}{\mathrm{v}}\right)
\end{aligned}
$$

Model:

Yoon-Nelson

$\ln \left(\frac{c_{t}}{c_{o}-C_{t}}\right)=k_{\mathrm{YN}} t-\mathrm{xh}_{\mathrm{YN}}$

where $k_{A B}$ is the kinetic constant (liters per milligram per minute), $\mathrm{N}_{0}$ is the maximum volumetric sorption capacity (milligrams per liter), $v$ is the linear flow rate (centimeters per minute), $\mathrm{Z}$ is the bed height in the column (centimeters), $\mathrm{k}$ is the adsorption rate constant (liters per milligram per minute), $\mathrm{k}_{\mathrm{YN}}$ is the kinetic constant (per minute), and $\tau$ (minute) is the time required for retaining $50 \%$ of the initial adsorbate concentration.

The data generated were fit into the linear forms of Yoon-Nelson and Adams Bohart models and respective parameters for each model and the $R^{2}$ values obtained for $10 \mathrm{~g}$ adsorbent and $3 \mathrm{ml} / \mathrm{min}$ are tabulated in table 1 . From the table, the value of $\tau(\mathrm{min})$ represent the time at which $50 \%$ of the adsorbent in the column would reach breakthrough point. The higher the value the better the performance of the column as similarly reported by Yagub et al. (2014), where $\mathrm{k}_{Y N}\left(\mathrm{~min}^{-1}\right)$ are the kinetic rate constants. Similarly, from table 1 , the values of the volumetric sorption capacity of the bed $\left(\mathrm{N}_{0}\right)$ presented implied that when effluent concentration reach those values at the reaction condition, the column has reached first saturation level which is different from exhaustion level attained when the normalized concentration reaches 0.9 . But considering the $\mathrm{R}^{2}$ value for the two models, the process relatively obey Adams Bohart model better than Yoon-Nelson model.

Table 1: Summary of the studied kinetic model parameters

\begin{tabular}{ll}
\hline Adams-Bohart Model & \\
\hline $\mathrm{R}^{2}$ & 0.842 \\
$\mathrm{~K}_{\mathrm{AB}}(\mathrm{L} / \mathrm{min} \mathrm{mg})$ & $0.5 \times 10^{-4}$ \\
$\mathrm{~N}_{\mathrm{o}}(\mathrm{mg} / \mathrm{l})$ & 35.788 \\
\hline Yoon-Nelson Model & \\
$\mathrm{R}^{2}$ & 0.795 \\
$\mathrm{~K}_{\mathrm{YN}}\left(\mathrm{min}^{-1}\right)$ & 298 \\
$\tau(\min )$ & 0.011 \\
\hline
\end{tabular}

\section{Conclusion}

In an effort to device a means of reducing environmental pollution through treating industrial waste waters especially those containing dye stuff in large scale and in a continuous process, the present study investigated the performance of AWC as a suitable adsorbent for dynamic removal of $M B$ from its aqueous solution using column chromatographic approach. This process is simple, convenient, economical and user friendly. Different characterization techniques such as UV-Visible spectrophotometry, FT-IR, $\mathrm{SEM}$ and $\mathrm{pH}_{\mathrm{pzc}}$ were carried out to establish the nature of the substrate and adsorbate surface and their respective interactions with each other. SEM pictures provided information on how the dye molecules diffused through the bulk, filled up the pores and adhere to the surface of the adsorbent. While FT-IR on the other hand showed the relative position of peaks and bands and how some of them shifted or even disappeared due to stretching vibration of functional groups involved in the adsorption process. The combined influence of all the functional groups of activated carbon determines $\mathrm{pH}_{\mathrm{pzc}}$, i.e., the $\mathrm{pH}$ at which the net surface charge on carbon was zero.

The column adsorption parameters were optimized and the maximum \%removal could be achieved by setting the level of process variables at $30 \mathrm{ppm}(\mathrm{mg} / \mathrm{L})$ initial dye concentrations, $28 \mathrm{~cm}$ bed height, and $3 \mathrm{~mL} / \mathrm{min}$ of feed flow rate. The fixed-bed adsorption system was found to perform well with lower initial dye concentration, higher adsorbent bed height, and lower feed flow rate. As the initial dye concentration increases, relative amount of dye adsorbed per unit mass of adsorbent also increased and subsequently increased the driving force for mass transfer and decreased the adsorption zone length. High adsorption capacity was observed at the highest bed height. This is because, increase in the surface area provided more binding sites for adsorption. Higher flow rate lead to lower adsorption capacity due to insufficient contact time required to attain equilibrium. 
The adsorption process has been explained using Adams-Bohart and Yoon-Nelson models, even though the values of correlation

\section{REFERENCES}

Agrawal, P., and Bajpai A. (2011). Dynamic column adsorption studies of toxic $\mathrm{Cr}(\mathrm{VI})$ ions onto iron oxide loaded gelatine nanoparticles, J. Dispersion Sci. Technol. 32 : 1353-1362.

Ahmad, A. A., Hameed, B. H. (2010). Fixed-bed adsorption of reactive azo dye onto granular activated carbon prepared from waste, J. Hazard. Mater. 175: 298-303.

Ajaero, C., Okolue, B.N., and Oze, R.N., (2010). Adsorption of Copper (II) by a Nigerian Brown Coal. JETEAS, 1(1):1-4.

Ayyappan, R., Sophia, A. C., Swaminathan, K., Sandhya, S. (2005). Removal of Pb(II) from aqueous solution using carbon derived from agricultural wastes, Process Biochem. 40:1293-1299.

Bohart, G. S. and Adams, E. Q. (1920). Behaviour of charcoal towards chlorine, $\mathrm{J}$. Chem. Soc. 42: 523-529.

Cui, L., Liu, C., Wu, G. (2008). Performance and mechanism of methylene blue biosorption on orange peel, Environ. Technol. 29; 1021-1030.

Dawood, S., and Sen,T. K. (2012). Removal of anionic dye congored from aqueous solution by raw pine and acid-treated pine cone powder as adsorbent: Equilibrium, thermodynamic, kinetics, mechanism and process design, Water Res. 46 :1933-1946.

Gupta, V., Ali, I., Saini, V. (2004). Removal of rhodamine $\mathrm{B}$, fast green, and methylene blue from wastewater using red mud, an aluminum industry waste, Ind. Eng.Chem. Res. 43 1740-1747.

Han, R. P., Wang, Y., Zhao, X., Wang, Y. F., Xie, F. L., Cheng, J. M., Tang, M. S. (2009). Adsorption of methylene blue by phoenix tree leaf powder in a fixed-bed column: Experiments and prediction of breakthrough curves, Desalination 245 : 284-297.

Meena, A. K., Mishra, G., Rai, P., Rajagopal, C., Nagar, P., (2005). Removal of heavy metal ions from aqueous solutions using carbon aerogel as an adsorbent, $J$. Hazard.Mater. 122: 161-170.

Mohammod, M., Sen, T. K., Maitra, S., Dutta, B. K. (2011). Removal of $\mathrm{Zn}^{2+}$ from aqueous coefficient $R^{2}$ were relatively not high, signifying poor correlation between the data as shown in Tables 1.

solution using castorseed hull, Water Air Soil Pollut. 215: 609-620.

Nethaji, S., Sivasamy, A., Vimal, R., Kumar, A., and Mandal, B. (2013). Preparation of Char from Lotus Seed Biomass and the Exploration of its Dye Removal Capacity Through Batch and Column Adsorption Studies, Environ Sci. Pollut Res 20:36703678: doi 10.1007/s11356-012-1267-4.

Sadaf, S. and Bhatti, H. N. (2014). Evaluation of peanut husk as a novel, low cost biosorbent for the removal of indosol orange RSN dye from aqueous solutions: Batch and fixed bed studies, Clean Technol. Environ. Policy 16: 527-544.

Sen, T. K., Mahajan, S., Khilar K. C. (2002). Colloid-associated contaminant transport in porous media: 1. Experimental studies, AIChE J. 48: 2366-2374

Tajana, P. and Nikola, K. (2006). Point Of Zero Charge And Surface Charge Density Of $\mathrm{TiO}_{2}$ In Aqueous Electrolyte Solution As Obtained By Potentiometric Mass Titration Croatica Chemica Acta Ccacaa79 (1): 95-106.

Vasques, A. R., Guelli, U. S., Selene, M. A., Valle, J. A. and Ulson de Souza, A. A. (2009). Removal of Dyes from the Textile Industry by Adsorption in Fixed Bed Columns: A Sustainable Process,"Chemical Product and Process Modeling: 4:7;1-11.

Yagub, M. T., Sen, T. K., and Ang, M. (2013). Removal of cationic dye methylene blue (MB) from aqueous solution by ground raw and base modified pine cone powder, Environ. Earth Sci. 13; 1-13.

Yagub, M. T., Sen, T. K., Afroze, S., and Ang, H. M. (2014). "Dye and its removal from aqueous solution by adsorption: A review," Adv. Colloid Interfac., 209: 172-184.

Yoon, Y. H. and Nelson, J. H. (1984). Application of gas adsorption kinetics I. A theoretical model for respirator cartridge service life, Am. Ind. Hyg. Assoc. J. 45: 509-516.

Yu, Z., Qi, T., Qu, J., Wang, L., Chu, J. (2009). Removal of $\mathrm{Ca}(\mathrm{II})$ and $\mathrm{Mg}(\mathrm{II})$ from potassium chromate solution on Amberlite IRC 748 synthetic resin by ion exchange, J. Hazard. Mater. 167 406-412. 